\title{
ABORDAGEM SOBRE O DESCARTE INADEQUADO DE LÂMPADAS FLUORESCENTES, PILHAS E BATERIAS NO ENSINO DE CIÊNCIAS
}

\author{
APPROACH ON INADEQUATE DISPOSAL OF FLUORESCENT LAMPS, \\ BATTERIES AND BATTERIES IN SCIENCE TEACHING
}

DOI: http://dx.doi.org/10.23926/RPD.2526-2149.2018.v3.n2.p492-505.id227

\section{Carlos Henrique \\ Damasceno \\ Licenciado em Ciências da \\ Natureza (IFMT). \\ kaikedamasceno@hotmail.co \\ $\underline{\mathrm{m}}$}

\section{Leandro Carbo \\ Doutor em Química. \\ Professor EBTT (IFMT). \\ leandro.carbo@svc.ifmt.edu. br}

\section{Roberta Lima Moretti \\ Mestra em Ensino de Física. Professora EBTT (IFMT). roberta.moretti@svc.ifmt.ed u.br}

\section{Gabriel Antonio Ogaya Joerke \\ Doutor em Sociologia. Professor EBTT (IFMT). gabriel.joerke@svc.ifmt.edu. br}

Resumo: O objetivo do presente trabalho foi aplicar e avaliar uma proposta didática sobre pilhas, baterias e lâmpadas fluorescentes, no ensino de Ciências, direcionada a estudantes do Ensino Fundamental de duas escolas públicas da cidade de Jaciara-MT. A pesquisa se baseia em uma abordagem qualitativa, tendo como instrumentos de coletas de dados: questionário, observação e diário de campo. Para o planejamento das atividades propostas, os estudantes foram investigados sobre as temáticas, por meio de questionários, de forma a verificar os conhecimentos prévios a respeito dos riscos ocasionados pelo descarte inadequado, destes materiais. Para evidenciar os riscos do descarte inadequado, foram utilizadas duas aulas expositivas/dialogadas e um desafio para o recolhimento dos materiais, que apresentou grande diferença, entre as escolas. Observou-se, por meio das respostas, que a maioria dos estudantes descartam suas pilhas, baterias e lâmpadas fluorescentes, no lixo doméstico, por não saber dos riscos que estes materiais podem causar à saúde e ao meio ambiente, por possuírem metais pesados que são liberados, no caso das pilhas, quando começam a enferrujar e nas lâmpadas fluorescentes, quando são quebradas.

Palavras-chave: Descarte inadequado. Pilhas e baterias. Lâmpadas fluorescentes.

\begin{abstract}
The objective of the present work was to apply and evaluate a didactic proposal on batteries, batteries and fluorescent lamps, in the teaching of science, directed to students of the elementary School of two public schools of the city of, The research is based on a qualitative approach, having as instruments of data collection, questionnaire, observation and Field Journal. For the planning of the proposed activities, the students were investigated on the subjects, by means of questionnaires, in order to verify the previous knowledge about the risks caused by the inappropriate disposal of these materials. To highlight the risks of inappropriate disposal, two expository/dialogue classes were used and a challenge for the collection of materials, which showed great difference between schools. It was observed, through the replies, that most students discard their batteries, batteries and fluorescent lamps in household waste, because they do not know the risks that these materials can cause to health and the environment, because they have heavy metals that are Released, in the case of batteries, when they start to rust and in fluorescent lamps, when they are broken.
\end{abstract}

Keywords: Improper disposal; Batteries; Fluorescent lamps. 


\section{INTRODUÇÃO}

A utilização de eletroeletrônicos pela população vem crescendo em grandes proporções e, em consequência, há um aumento da utilização de pilhas e baterias. Algumas pilhas têm vida útil consideravelmente baixa, com isso, o meio de descarte procurado pela maioria é o lixo comum, mas esta atitude pode trazer problemas ao meio ambiente e saúde humana. Segundo a Associação Brasileira da Indústria Elétrica e Eletrônica (ABINEE), o mercado brasileiro produz por ano, mais de 800 milhões de unidades de pilhas comuns e alcalinas (BRASIL, 1999).

Com a utilização de Mp3 players e câmeras digitais, a demanda por pilhas tornou-se mais frequente; as não recarregáveis, por apresentarem vida útil menor, acarretam um custo elevado para o consumidor, na utilização desses aparelhos. Nesse sentido, surgiram no mercado, as baterias recarregáveis ou conhecidas como pilhas recarregáveis. Para reutilizar pilhas convencionais, algumas pessoas as colocam para serem recarregadas, entretanto, devido sua composição química, isso não é recomendado. Nesse sentido, quando submetidas a esse processo, pode ocorrer vazamentos do líquido interno (os metais presentes e demais componentes) e em alguns casos, explosões (CABRAL et al., 2014).

Além dos materiais citados, as lâmpadas fluorescentes podem provocar danos ao meio ambiente, quando são descartadas de forma inadequada. São as lâmpadas mais procuradas no mercado consumidor, por apresentarem alta durabilidade, economia de energia, iluminarem mais que as incandescentes (MASCIA, 2011) e serem menos dispendiosas que as do tipo LED. Segundo Melo et al., (2011), o Brasil produz cerca de 100 milhões de lâmpadas fluorescentes por ano, número muito preocupante, considerando que a maioria será descartada de forma incorreta, no lixo comum.

A população, de forma geral, não sabe que na composição das lâmpadas fluorescentes há a presença de elementos químicos tóxicos, sendo o principal, o mercúrio, um metal pesado, liberado durante o estilhaçamento da lâmpada, proveniente do descarte inadequado, acarretando problemas à saúde humana e ao meio ambiente. Uma lâmpada fluorescente de $40 \mathrm{~W}$ possui em torno de $21 \mathrm{mg}$ de mercúrio, em sua composição, essa quantidade pode contaminar 15 mil litros de água (CESTARI; MARTINS, 2015).

Atualmente, existe a Política Nacional de Resíduos Sólidos - PNRS (BRASIL, 2012), que considera as lâmpadas fluorescentes como resíduos perigosos, de classe I. Recebem esta classificação, todos os materiais que apresentem periculosidade ou características inflamáveis, corrosivas, reatividade, toxidade e patogenicidade. Esta lei responsabiliza as empresas revendedoras pela recolha e destino final, desses materiais. 
Alguns artigos demonstram que a população descarta de maneira inadequada pilhas, baterias e lâmpadas fluorescentes por não saberem a composição química e os ricos ocasionados pelas mesmas para a saúde e meio ambiente (SANTOS; PENNA, 2016, MELO et al., 2011, BACILA et al., 2014, LARUCCIA et al., 2011).

Vê-se uma grande necessidade de sensibilizar os estudantes das escolas, quanto à importância do descarte correto de lâmpadas fluorescentes, pilhas e baterias. Na cidade de Jaciara, a Secretaria de Agricultura e Meio Ambiente, em parceria com a Prefeitura Municipal e as escolas, possui um projeto para a recolha desses materiais, os quais deveriam ser destinados até uma loja revendedora. Entretanto, o projeto não tem funcionado nas escolas, ou seja, não tem enviado ou motivado seus estudantes a fazerem a destinação correta destes materiais.

Diante do contexto, o presente trabalho teve por objetivo a sensibilização dos estudantes do Ensino Fundamental II, de duas escolas públicas do município de Jaciara-MT, quanto aos perigos do descarte inadequado de lâmpadas fluorescentes, pilhas e baterias, apresentando-lhes alternativas de descartes, corretos. A proposta didática foi construída, considerando os hábitos de descarte dos estudantes e os seus conhecimentos prévios, com relação aos riscos relacionados ao descarte inadequado, dos materiais.

\section{REFERENCIAL TEÓRICO}

Os professores eram considerados como os detentores do saber, conforme relata Brasil (1998, p. 19). Talvez por este motivo, os mesmos não buscavam aprimoramentos nas metodologias de ensino e atualização, sobre fatos cotidianos. Sasseron (2015) enfatiza que para se ensinar Ciências, é preciso saber que o mundo está em constantes modificações, sendo importante, a busca por novas formas para conhecer os fatos do cotidiano.

Contudo, muitos professores que não buscam formas de aprimoramentos, detêm-se apenas aos livros didáticos, não relacionando o conteúdo com o cotidiano do estudante, não despertando um espírito investigativo, nos mesmos. Nesse sentido, Brasil (1998; p. 27) reporta que:

\footnotetext{
Assim, o estudo das Ciências Naturais de forma exclusivamente livresca, sem interação direta com os fenômenos naturais ou tecnológicos, deixa enorme lacuna na formação dos estudantes. Sonega as diferentes interações que podem ter com seu mundo, sob orientação do professor. Ao contrário, diferentes métodos ativos, com a utilização de observações, experimentação, jogos, diferentes fontes textuais para obter e comparar informações, por exemplo, despertam o interesse dos estudantes pelos conteúdos e conferem sentidos à natureza e à ciência que não são possíveis ao se estudar Ciências Naturais apenas em um livro.
} 
A ciência na atualidade deve ser aprendida, associando a tecnologia às questões sociais e ambientais, por ser o meio mais apropriado para estabelecer uma relação entre humano e natureza e possibilitar o desenvolvimento de uma consciência planetária (Brasil, 1998). Por isso, cabe a necessidade de se estabelecer uma relação entre a educação ambiental e o ensino de Ciências.

O estudante deve ter a capacidade de perceber que a tecnologia veio como meio para suprir as necessidades humanas, tal como a criação da iluminação com origem em 1854, quando Heinrich Göbel inventou a primeira lâmpada incandescente, feita com um bulbo de vidro no qual retirou todo o ar e um filamento de bambu e o ligou a uma bateria. Mas o modelo comercial da lâmpada incandescente teve origem em 1879, quando inventada por Thomas Alva Edison, que criou uma base rosqueável, podendo ser ligada à energia elétrica. Essa lâmpada se originou com um filamento de fibra de carbono (OSRAM, 2010).

Atualmente, as questões ambientais têm sido motivo de grande preocupação para todos, devido aos problemas relacionados à escassez da água, afetando a produção de energia. De forma a reduzir o consumo de energia, o governo brasileiro publicou uma portaria interministerial $\mathrm{n}^{\circ}$ 1.007, em dezembro de 2010, com a intenção de banir as lâmpadas incandescentes do mercado, de forma gradativa (BASTOS, 2011), sendo, hoje, proibida a venda desse tipo de lâmpada.

A população tem procurado substituir as lâmpadas incandescentes por lâmpadas de mercúrio, também conhecidas como fluorescentes, pois são mais econômicas, possuem vida útil mais elevada, e por sua eficiência luminosa. Entretanto, a maioria não sabe, que essas apresentam, em sua composição, o mercúrio, um metal pesado que pode ocasionar problemas ambientais e para a saúde, por ser acumulativo, no organismo.

De forma a substituir as lâmpadas incandescentes com segurança ao meio ambiente e à saúde, surgiu, no mercado, a lâmpada de Diodo Emissor de Luz (LED), que possui uma vida útil mais elevada que as lâmpadas fluorescentes e, consequentemente, seu preço, no mercado consumidor, é elevado.

Segundo Santos et al. (2015), as lâmpadas de LED são as mais econômicas, porque possuem uma durabilidade e eficiência luminosa maior. Emitem luz sem gastar muita energia, podem durar cinco vezes mais que as fluorescentes e vinte vezes mais que as incandescentes. Essas lâmpadas, também, não oferecem riscos para a saúde, pois não possuem mercúrio em sua composição, e podem ser descartadas em lixo comum, sem se preocupar com riscos ao meio ambiente ou ao ser humano. 
Embora as lâmpadas LED apresentem vida útil maior e menos gasto de energia; as fluorescentes ainda são as mais procuradas no mercado, como substitutas das incandescentes, por serem econômicas, ter uma eficiência luminosa alta e o preço, em relação a lâmpadas LED, mais acessível. A vida útil desse tipo de lâmpada, de acordo com Bastos (2011), pode variar de 3.000 até 15.000 horas, dependendo da marca.

As lâmpadas fluorescentes são mais econômicas que as incandescentes, duram mais, todavia estes benefícios não compensam seus riscos, se descartadas, de forma inadequada, pois o mercúrio que elas contêm é cumulativo, pode causar vertigens, distúrbios neurológicos, interfere nas funções metabólicas, edemas pulmonares, aumenta o risco de ataques cardíacos, tremores e, em caso de mulheres grávidas, o mercúrio passa a barreira placentária e atinge o feto, se acumulando no tecido cerebral (SOUZA; BARBOSA, 2000).

Há muitos autores que relatam sobre o descarte de lâmpadas fluorescentes, evidenciando preocupações sobre o descarte inadequado, contextualizando com o cotidiano. Lima (2016), relaciona o descarte com o ensino de Ciências, Cunha et al., (2008) trazem o assunto sobre lâmpada, como um tema motivador no Ensino Médio e Rodrigues et al., (2015) mencionam os riscos deste descarte para a saúde humana.

Considerando os riscos ambientais que as lâmpadas fluorescentes podem provocar, foi criada a Resolução ${ }^{\circ} 257$ de 30 de junho de 1999, que visa disciplinar o descarte, manejo, reciclagem ou disposição final de pilhas e baterias usadas (REIDLER; GÜNTHER, 2002). Segundo a resolução, pilhas e baterias, que possuem em sua composição os elementos como cádmio, chumbo, mercúrio e seus componentes, ao término de sua vida energética, devem ser devolvidas aos comércios que as revendem ou a assistências técnicas, para que estes repassem para os fabricantes ou importadores, para viabilizarem o fim adequado a estes materiais.

Estes materiais precisam ser destinados de forma correta, pois em sua composição, metais pesados como o níquel, chumbo, cádmio, cobre, manganês, zinco, mercúrio, entre outros, quando dispostos no meio ambiente, podem causar contaminação por inalação, ingestão ou contato com a pele e, uma vez contaminado, o metal não é eliminado pelo organismo, podendo causar várias doenças como lesões cerebrais, disfunção renal e pulmonar (ROA, 2009).

Muitos autores têm se preocupado com o descarte inadequado de pilhas e baterias, procurando meios de relacionar esse assunto com os conteúdos escolares, como Araújo et al,. (2013) e Firme et al., (2008), que relacionam o descarte com o ensino de Química. Sobarzo e Marin (2010); Morozesk e Coelho (2016), interessados em abordar este tema no Ensino 
Fundamental, apresentam-no dentro do assunto mais geral, lixos eletrônicos; Kemerich et al., (2012), buscaram entender qual a percepção sobre o descarte indevido de pilhas e baterias, em habitantes de um município brasileiro, bem como, quais são os hábitos de descarte dos mesmos. Já Oliveira e Pereira (2016), propuseram um sistema de coleta desses eletrônicos, dentro de instituições de Ensino Superior.

\section{Metodologia}

O trabalho foi realizado em duas escolas públicas de Jaciara-MT, no período de 23 de outubro a 15 de dezembro de 2017. Na Escola "B", localizada em bairro periférico (bairro Jardim Aeroporto), as atividades foram realizadas com a turma do $9^{\circ}$ ano, e na Escola "A", situada no centro, foram realizadas atividades com as quatro turmas de $9^{\circ}$ ano, totalizando 94 estudantes pesquisados.

O estudo se enquadra como uma pesquisa de campo, de caráter qualitativo e de cunho descritivo. Pesquisa de campo é aquela aplicada com intuito de obter informações e/ou um entendimento sobre um determinado problema. Quanto ao objetivo, a pesquisa é exploratória, pois, considerando o que afirma Gil (2010, p. 27), este estudo também tem "como principal finalidade desenvolver, esclarecer e modificar conceitos e ideias, tendo em vista a formulação de problemas mais precisos ou hipóteses pesquisáveis para estudos posteriores". Como instrumento de coletas de dados, foram utilizados questionários e observações, durantes as atividades desenvolvidas, além de diário de campo.

\subsection{ATIVIDADES REALIZADAS}

Na primeira etapa foram aplicados dois questionários para todos os estudantes, nas duas escolas, de forma a avaliar a utilização e o conhecimento sobre os perigos do descarte inadequado de pilhas, baterias e lâmpadas, para o meio ambiente. O segundo questionário abordou a utilização de aparelhos que funcionam com pilhas ou baterias (1), as consequências do descarte inadequado (2), se a cidade possui pontos de recolhas (3) e qual o local de descarte desse material (4).

O primeiro questionário teve como objetivo, identificar se os estudantes conhecem as diferenças entre os três tipos principais de lâmpadas (1), quais os malefícios do descarte adequado das mesmas (2), o tipo de lâmpada que possuíam (3), o porquê da escolha desse tipo lâmpada (4), como é realizado o descarte desse material (5) e se na cidade existe ponto de recolha (6). 
Após análise das respostas dos estudantes, aos questionários, aconteceu a segunda etapa, na qual foi ministrada, em cada turma, aula expositiva/dialogada, apresentando a história do surgimento das pilhas, baterias e lâmpadas (com ênfase maior nas fluorescentes), evidenciando os benefícios para a sociedade e os riscos para o meio ambiente e saúde humana, em função do descarte incorreto, relacionando os conteúdos com o cotidiano e com a realidade dos estudantes.

A terceira etapa, ponto chave da sensibilização do trabalho, foi o recolhimento das pilhas, baterias e lâmpadas fluorescentes, colocando um ponto de coleta em cada turma, nas duas escolas, de forma que os mesmos, durante um período de 25 dias, teriam que trazer todos esses materiais que estivessem em suas casas ou jogados pela cidade. Após esse período, um representante de cada turma foi, junto com o pesquisador, encaminhar todo o material recolhido para uma empresa da cidade, que tem um convênio com a Secretaria de Meio Ambiente, para destinação final. Os pontos de coletas podem ser observados na Figura 1, A - ponto de recolha, colocado nas turmas da escola "A" e B - ponto de recolha da escola "B".

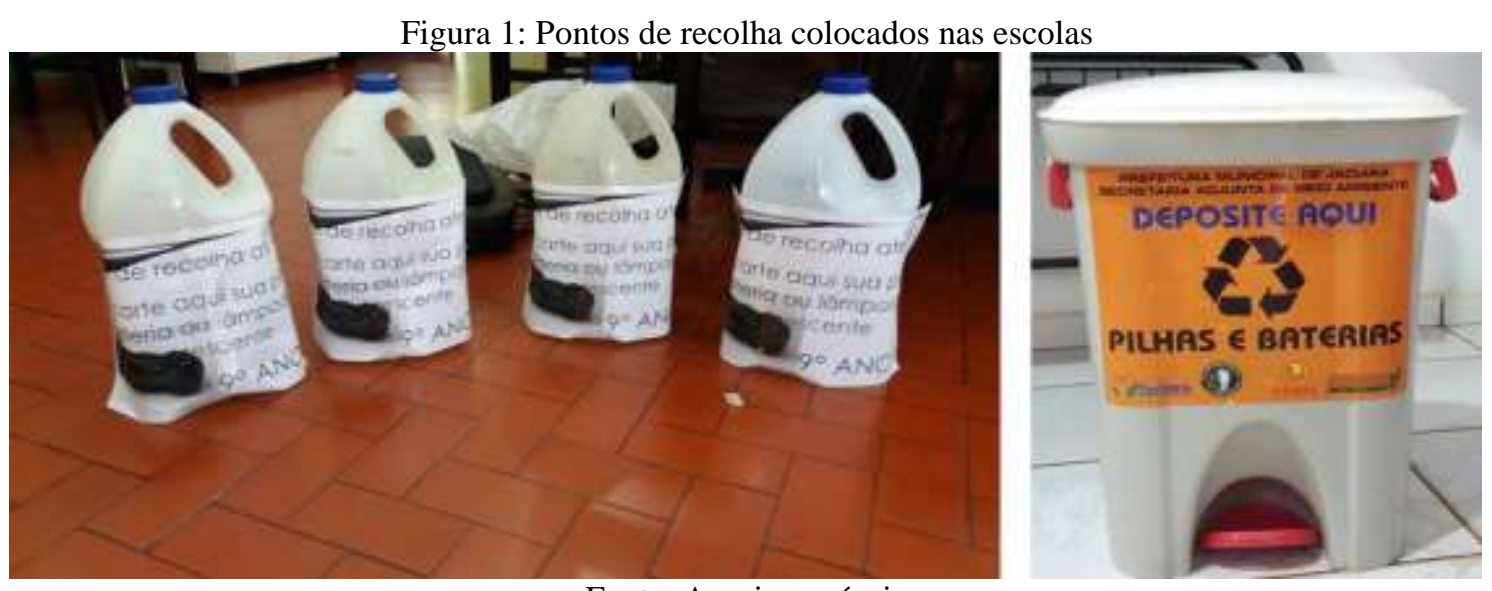

Fonte: Arquivo próprio

\section{Resultados E Discussões}

\subsection{INVESTIGAÇÃO DOS CONHECIMENTOS PRÉVIOS DOS ESTUDANTES, QUANTO À} UTILIZAÇÃO E DESCARTE DE PILHAS, BATERIAS E LÂMPADAS FLUORESCENTES

A ideia de realizar o trabalho em duas escolas, foi para constatar se havia diferença na utilização desses materiais, em suas residências e, principalmente, quanto à preocupação ambiental por parte dos estudantes, no que diz respeito ao descarte dos mesmos. Desta forma, foi verificado que há diferenças entre os dois ambientes, principalmente nas informações de coleta e perigos desses materiais, nos quais $69 \%$ dos estudantes da escola "B", alegaram que, em sua cidade não havia ponto de recolha para pilhas, baterias e lâmpadas fluorescentes e não sabiam se estes materiais poderiam causar-lhes risco. Já na escola “A”, 65\% dos estudantes 
responderam que o descarte desses materiais, poderia causar riscos e que conheciam que na cidade, havia um ponto de recolha para esses materiais.

Verificou-se ainda, que todos os estudantes possuem acesso a aparelhos que funcionam com fonte de alimentação a pilhas ou baterias. A respeito do descarte de pilhas e baterias, quando findado sua vida útil, observou-se que na escola "B", $87 \%$ dos pesquisados descartam, de forma inadequada, no lixo comum. O restante afirmou separar estes materiais para a coleta seletiva. Na escola "A", $60 \%$ dos estudantes responderam, que jogam no lixo comum e, somente $3 \%$ disseram que separam, para a coleta seletiva. Nesta escola, notou-se algo incomum, pois $37 \%$ dos pesquisados afirmaram que guardam em suas residências, sem mencionar o que fazem, após isso.

Foi perguntado aos estudantes se os mesmos sabiam que em sua cidade havia um ponto de recolha para esses materiais e $92 \%$ dos estudantes da Escola "B" responderam que não, sendo que a própria escola está cadastrada na Secretaria de Agricultura e Meio Ambiente do município, como um ponto de recolha. Nessa mesma escola, observou-se que $65 \%$ dos estudantes acreditam que o descarte desses materiais não causa riscos ao meio ambiente. Além disso, pode-se considerar que os mesmos descartam, de forma inadequada, pois não sabem onde há pontos de recolha, e consideram que esses materiais não causam riscos. Na Escola " $\mathrm{A}$ ”, $65 \%$ responderam que em sua cidade, existe ponto de coleta, mencionando a Secretaria de Agricultura e Meio Ambiente e a Associação Ecológica e Meio Ambientalista (AEMA). Além disso, 95\% afirmaram que o descarte pode causar riscos para a saúde e o meio ambiente, entretanto não souberam especificar quais. Observou-se ainda que, mesmo conhecendo a existência dos pontos de recolha e a possibilidade de riscos à saúde, $60 \%$ dos alunos descartam esses materiais, de maneira incorreta.

Reidler e Günther (2002) verificaram resultados similares, em estudo realizado em um município do estado de São Paulo, com 86 pessoas categorizadas em quatro grupos: consumidores, fornecedores, revendedores e especialistas no assunto. Os autores verificaram que a maioria dos pesquisados desconhecia a legislação sobre o descarte correto de pilhas e baterias, e que descartava de forma inadequada, ou ainda, guardava os materiais em suas residências, o que, na maioria das vezes, eram descartados no lixo comum.

A análise do questionário sobre lâmpadas evidenciou, que em ambas as escolas, a maioria dos estudantes não sabia apontar as diferenças entre os tipos. Alguns afirmaram que as incandescentes gastam mais energia do que as demais e iluminam menos que as fluorescentes. Observou-se ainda, que a fluorescente é a mais utilizada nas residências dos estudantes, e que 
$86 \%$ as descartam no lixo comum, quando apresentam defeitos ou simplesmente não funcionam mais; apenas $13 \%$ afirmaram que separam para a coleta seletiva. Assim, como as pilhas e baterias, as lâmpadas não possuem uma política de recolha, então, pode-se dizer, que estes materiais acabam sendo descartados, no aterro da cidade.

Pode-se verificar que a maioria dos estudantes não sabem quais riscos o descarte inadequado das lâmpadas pode causar ao meio ambiente e, por isso, acabam destinando para o lixo comum. Melo et al. (2011) também observaram esta problemática, em trabalho realizado na cidade de Montes Claros-MG, quando notaram que todos os seus pesquisados possuíam, em suas residências, lâmpadas do tipo fluorescentes e, quando questionados sobre a destinação desses materiais, a maioria afirmou descartar em lixo comum.

$\mathrm{Na}$ cidade de Jaciara, onde a pesquisa foi realizada, não há ponto de recolha para lâmpadas fluorescentes; o que tem, é uma loja que recebe este tipo de material, mas somente de clientes da mesma. Já para pilhas e baterias, algumas lojas que vendem, fazem a recolha. Contudo, os proprietários destas lojas têm um custo financeiro, para destinação correta desses materiais, pois, segundo a legislação, todos os comércios que comercializam lâmpadas fluorescentes, pilhas e baterias, devem receber os mesmos, quando não funcionam mais. Entretanto, poucos fazem esse papel e, nesse caso, falta uma fiscalização por parte dos municípios, para que a lei seja cumprida.

\subsection{AULA EXPOSITIVA/DIALOGADA E RECOLHA DOS MATERIAIS}

Durante a aula, foi comentado com os estudantes, sobre um histórico e utilização de pilhas e baterias. Os estudantes relataram que era impossível uma pessoa não ter alguma coisa que funciona, com fonte de alimentação pilhas e baterias. Os mesmos, também, não sabiam como surgiu a primeira pilha e seu funcionamento, quais eram os elementos químicos que a compõe e seus riscos para a saúde humana e para o meio ambiente.

Por meio do questionário, notou-se que os estudantes não sabiam diferenciar os tipos de lâmpadas existentes e, pensando nisso, foi abordado, na aula, esse conteúdo, apresentando um histórico sobre o assunto, no qual os estudantes demostraram saber quem foi o criador desse tipo de lâmpada. Quando mencionado sobre os benefícios da lâmpada tipo LED, os estudantes ficaram atentos e entenderam a economia de energia que a mesma traz, entretanto, comentaram que seus pais não optam por comprar essa lâmpada, por possuir preço maior que as fluorescentes. 
Em seguida, quando foi mencionado sobre as lâmpadas fluorescente, os riscos das mesmas, quando descartadas de forma inadequada, alguns estudantes afirmaram, que em alguns casos, quebram as mesmas e colocam com cola na linha de suas pipas, não sabendo que esse costume trazia riscos para a saúde.

Os estudantes demonstraram muita curiosidade e preocupação, ao ser mencionado que os metais que compõem as pilhas, baterias e lâmpadas, podem causar doenças que afetam o sistema nervoso central, o fígado, os rins e os pulmões. O cádmio é cancerígeno, o chumbo pode provocar anemia, debilidade e paralisia parcial, e o mercúrio pode, também, causar mutações genéticas, com isso, os mesmos ficaram atentos aos riscos, e comentaram que procurariam descartar estes materiais de forma adequada, após verem os riscos que eles podem trazer (TANAUE et al. 2015; LOPES; SILVA, 2013).

Quando foi mencionado que ambas as escolas são pontos de recolhas de pilhas e baterias, cadastrados na Secretaria de Meio Ambiente da cidade, todos ficaram surpresos, afirmaram que não sabiam e que ninguém havia comentado sobre isso, para os mesmos.

Após o termino da aula expositiva/dialogada, foi proposto, aos estudantes, uma competição de recolha de pilhas, baterias e lâmpadas fluorescentes, num período de 25 dias; a Figura 2 apresenta os materiais coletados pelos estudantes da Escola "A".

Figura 2: Material coletado na Escola "A"

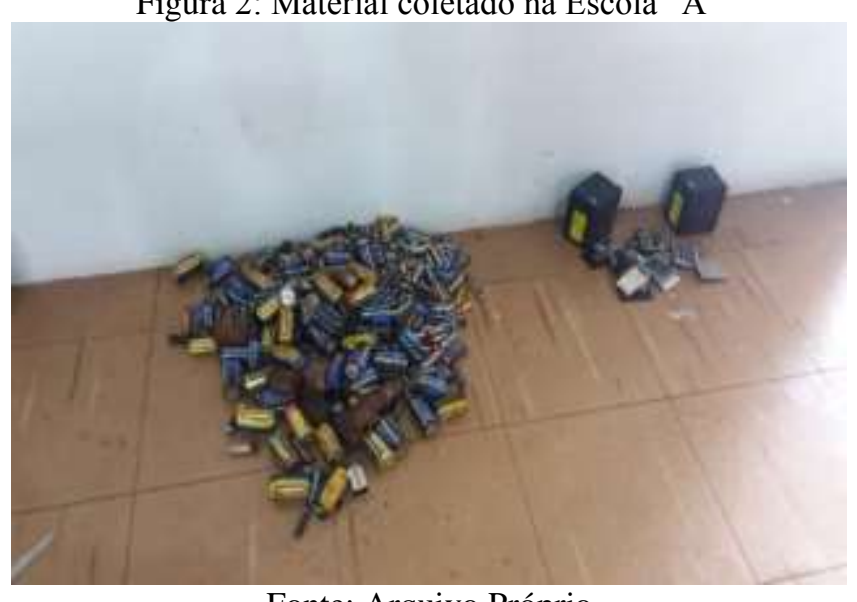

Fonte: Arquivo Próprio

$\mathrm{Na}$ Escola "A", os estudantes se mostraram entusiasmados com a competição, onde foram recolhidos $30 \mathrm{~kg}$ de pilhas e baterias e somente uma lâmpada fluorescente. A professora regente relatou que os estudantes ficaram animados com a competição proposta, que saíram procurando estudantes de outras turmas para descartarem as pilhas ou baterias. Todavia, na Escola "B", os estudantes se mostraram entusiasmados com a aula teórica, mas não recolheram 
nenhum tipo de material. No mesmo período, o ponto de recolha virou um reservatório para garrafas de vidro.

Após recolher os materiais, estes foram levados para o Centro de Referência de Jaciara (IFMT/SVC), onde foi feito a separação das pilhas e baterias. Em seguida, comunicou-se à Secretaria de Agricultura e Meio Ambiente da cidade, para a destinação correta dos mesmos, ocasião em que esta se mostrou indiferente quanto ao volume de lixo recolhido, afirmando que a prefeitura estava em crise e que eles não poderiam recolher este material, em virtude de não dispor de recursos financeiros para pagar a empresa que iria fazer o descarte adequado.

Diante disso, foi realizado, na cidade de Jaciara, um levantamento para verificar se havia alguma empresa que recolhesse lâmpadas fluorescentes ou se poderia recolher o que foi coletado na escola. Nas lojas de materiais para construção da cidade, que vendem esse tipo de lâmpada, os funcionários afirmaram que não sabiam como destinar este material, pois os mesmos descartavam em lixos comuns. Em seguida, procurou-se a loja revendedora de lâmpadas, que estava cadastrada junto à Secretaria de Meio Ambiente, para verificar se receberiam o material coletado, onde foi informado que não poderia receber, pois já estava com muito material coletado e que a secretaria não estava fornecendo suporte financeiro para descartar estes materiais.

Outras lojas foram procuradas para verificar se teriam interesse na recolha desses materiais, entretanto, todas afirmaram que não receberiam. Uma loja afirmou que já havia firmado um contrato de parceria com a prefeitura, entretanto, o ano de 2016 se encerrou e a loja nunca mais foi procurada pela mesma. Dessa forma, percebe-se um dado preocupante sobre isso, pois são materiais muito utilizados pela população, que são descartados no lixo comum, podendo trazer sérios problemas de poluição do meio ambiente e que o órgão que poderia fiscalizar, não está cumprindo a legislação.

Como não conseguimos que nenhuma loja e nem a prefeitura recebessem o material coletado na escola A, armazenamos no Instituto Federal de Mato Grosso e, ao mesmo tempo, estamos procurando empresas em outras cidades, que fazem esse tipo de coleta, para encaminhamento das pilhas, baterias e a lâmpada fluorescente, recolhidos.

Para melhorar a aprendizagem do aluno, o professor deve abordar os conteúdos da disciplina de Ciências, de forma contextualizada, buscando relacioná-los com o cotidiano do estudante. Percebeu-se, durante o desenvolvimento da pesquisa, que estes se mostraram interessados pelo tema proposto e verificaram a importância de conhecer os malefícios que as 
pilhas, baterias e lâmpadas fluorescentes podem provocar ao meio ambiente, quando descartados no lixo comum.

\section{CONSIDERAÇÕES FINAIS}

Por meio do questionário aplicado, notou-se que a maioria dos estudantes pesquisados e seus familiares, descartam as pilhas, baterias e lâmpadas fluorescentes no lixo comum, não conhecendo os riscos que estes materiais podem causar para a saúde e ao meio ambiente.

Através da aula expositiva, pode-se constatar que os estudantes não sabiam dos riscos que os componentes das pilhas, baterias e lâmpadas fluorescentes podem causar aos mesmos ou ao meio ambiente, se descartados de forma imprópria. Entretanto, durante a realização da mesma e na atividade lúdica, verificou-se a sensibilização dos estudantes sobre os perigos destes materiais para o meio ambiente, quando descartados de formas inadequadas.

Relacionar o conteúdo com o cotidiano dos estudantes, torna-se necessário, pois demonstra fatos da ciência que fazem parte da vida dos mesmos e revela que o descarte inadequado, destes materiais, pode afetá-los a longo prazo.

\section{REFERÊNCIAS}

ARAÚJO, N. G.; SILVA, G. N.; ARAÚJO, P. M. A. G.; FURTADO, T. F. Descarte Inadequado de Pilhas e Baterias: Contextualização do Ensino de Química Através de Aulas Práticas. In: 5 Congresso Norte Nordeste de Química. Anais, 2013.

BACILA, D. M.; FISCHER, K.; KOLICHESKI, M. B. Estudo sobre reciclagem de lâmpadas fluorescentes. Eng. sanit. ambient, v. 19, n. esp., p. 21-30, 2014.

BASTOS, F. C. Análise da política de banimento de lâmpadas incandescentes do mercado brasileiro. COPPE-UFRJ, Rio de Janeiro, 2011.

BRASIL - Associação Brasileira da Indústria Elétrica e Eletrônica (ABINEE). Parecer do Ministério da Saúde sobre a proposta de revisão da Resolução n ${ }^{\circ} 257$ de 30 de julho de 1999 do Conselho Nacional do Meio Ambiente, que trata do gerenciamento de pilhas e baterias em Território Nacional. Disponível em (http://www.mma.gov.br/port/conama/processos/0330EB12/ParecerTec07008_MSaude.pdf) Acesso em 12/05/2017.

BRASIL. [Lei n. 12.305, de 2 de agosto de 2010]. Política nacional de resíduos sólidos [recurso eletrônico]. - 2. ed. - Brasília : Câmara dos Deputados, Edições Câmara, 2012. 73 p. - (Série legislação; n. 81)

BRASIL. Secretaria de Educação Fundamental. Parâmetros Curriculares Nacionais: Ciências Naturais / Secretaria de Educação Fundamental. Brasília: MEC/SEF, 1998. 138 p. 
CABRAL, U. S.; SCALZER, B. L.; VASSOLER, J. V.; SANTOS, M. C. Uso e descarte correto de pilhas e baterias: uma campanha para conscientização ambiental. In: X Congresso Nacional de Excelência e Gestão, Anais, Rio de Janeiro, 2014.

CESTARI, W.; MARTINS, C. H. Logística reversa de lâmpadas fluorescentes pós-consumo estudo de caso: sistema de armazenagem em uma instituição de ensino. Electronic Journal of Management, Education and Environmental Technology (REGET), v. 19, n. 3, p. 124$135,2015$.

CUNHA, A. J.; ALFAYA, R. V. S.; GIMENEZ, S. M. N.; ALFAYA, A. A. S. Lâmpadas fluorescentes como tema motivador no ensino médio. In: XIV Encontro Nacional de Ensino de Química (XIV ENEQ), Curitiba. Anais. Curitiba - PR, 2008.

FIRME, R. N.; AMARAL, E. M. R.; BARBOSA, R. M. N. Análise de uma sequência didática sobre pilhas e baterias: uma abordagem CTS em sala de aula de química. In: XIV Encontro Nacional de Ensino de Química (XIV ENEQ), Curitiba. Anais. Curitiba - PR, 2008.

GIL, A. C. Métodos e técnicas de pesquisa social. 7. ed. São Paulo: Atlas, 2010.

KEMERICH, P. D. C.; MENDES, S. A.; VORPAGEL, T. H.; PIOVESAN, M. Descarte indevido de pilhas e baterias: a percepção do problema no Município de Frederico Westphalen-RS. Revista Eletrônica em Gestão, Educação e Tecnologia Ambiental, v. 8, n.8, p. 1680-1688, 2013.

LARUCCIA, M. M.; NASCIMENTO, J. V.; DEGHI, G. J.; GARCIA, M.G. A Study of consumer behavior on recycling of fluorescent lamps in São Paulo, Brazil. International Journal of Business Administration, v. 2, n. 3, p. 101-112, 2011.

LIMA, B. M. Ensino de Ciências: temática lâmpadas com enfoque CTSA. 59 f. Trabalho de Conclusão de Curso (Graduação). Universidade Federal do Pampa, Dom Pedrito, 2016.

LOPES, J. A.; SILVA, F. B. Conhecendo os riscos ambientais causados pelo descarte inadequado de pilhas e discutindo a implementação de ações ambientalmente sustentáveis. In: III Encontro de Iniciação a Docência da UEPB, Campina Grande. Anais ENID/UEPB. Campina Grande: Realize Eventos e Editora, 2013. v. 1.

MASCIA, A. R. Estudo comparativo entre lâmpadas fluorescentes compactas e lâmpadas incandescentes, considerando a viabilidade econômica. 70 f. Trabalho de Conclusão de Curso (Graduação). Universidade Federal do Pampa, Alegrete, 2011.

MELO, M. M. A. P.; VIANA, T. A.; PEREIRA, S. C. M.; ALVES, R. G. Análise da viabilidade da implantação da coleta e disposição adequada das lâmpadas fluorescentes na cidade de Montes Claros - MG. In: 26 CONGRESSO BRASILEIRO DE ENGENHARIA AGRÍCOLA E AMBIENTAL. Anais. 2011.

MOROZESK, M.; COELHO, G. R.. Lixo Eletrônico "Uso e Descarte": uma proposta de intervenção em uma Escola Pública de Vitória-ES. Revista Brasileira de Pesquisa em Educação em Ciências, v. 16, n. 2, p. 317-338, 2016. 
OLIVEIRA, V. C.; PEREIRA, N. A. Educação ambiental sistema de coleta para destino final de pilhas e baterias: uma alternativa sustentável em instituições de ensino superior. XIV O Fórum Latino Americano de Engenharia e Sustentabilidade, ENEEAmb, Brasília - DF, 2016.

OSRAM, 2010. Lâmpadas Incandescentes - Catálogo Geral 2009-2010 - Disponível em:

<http://www.osram.com.br/osram_br/Ferramentas_\%26_Catlogos/Downloads/Iluminac ao_Geral/Catalogo_Geral_2009-2010/index.html>.Acesso em: 23 de janeiro de 2017.

REIDLER, N. M. V. L.; GÜNTHER, W. M. R. Percepção da população sobre os riscos do descarte inadequado de pilhas e baterias usadas. In: CONGRESSO INTERAMERICANO DE INGENIERÍA SANITARIA Y AMBIENTAL. Anais. Cancún, 2002. p. 27-31.

ROA, K. R. V. SILVA, G. NEVES, L. B. U. WARIGODA, M. S. Pilhas e baterias: usos e descartes x impactos ambientais. Caderno do professor. GEPEQ- USP: curso de formação continuada de professores, 2009. Disponível em:

<http://www.cienciamao.if.usp.br/dados/aas/_indefinidopilhasebateria.arquivo.pdf>. Acessado em: 08/09/2017.

RODRIGUES, F.; SANTANA, G. S.; ALDIB, R.; NETO, L. M. R. Os riscos para a saúde humana oriundo do descarte inadequado de pilhas, baterias e lâmpadas. In: IV Simpósio de ciências farmacêuticas. Centro Universitário São Camilo. Anais. São Paulo - SP, 2015.

SANTOS, T. S.; BATISTA, M. C.; POZZA, S. A; ROSSI, L. S. Análise da eficiência energética, ambiental e econômica entre lâmpadas de LED e convencionais. Eng Sanit. Ambient, v. 20, n. 4, p. 595-602, 2015.

SANTOS, V. A. C.; PENNA, L. F. R. Descarte de Pilhas e Baterias: Estudo de Caso no Instituto Federal de Minas Gerais, Campus Governador Valadares - MG. In: VII Congresso Brasileiro de Gestão Ambiental, Universidade Federal de Campina Grande. Anais. Campina Grande/PB, 2016.

SASSERON, Lúcia Helena. Alfabetização científica, ensino por investigação e argumentação: relações entre ciências da natureza e escola. Ensaio Pesquisa em Educação em Ciências (Belo Horizonte), v. 17, n. esp., p. 49-67, 2015.

SOBARZO, L. C. D.; MARIN, F. A. D. G. Resíduos sólidos: representações, conceitos e metodologias: propostas de trabalho para $\mathrm{O}$ ensino fundamental. Revista de Ensino de Geografia, v. 1, n. 1, p. 3-14, 2010.

SOUZA, J. R.; BARBOSA, A. C. Contaminação por mercúrio e o caso da Amazônia. Química Nova na Escola. São Paulo, n. 12, p. 3-7, 2000.

TANAUE, A. C. B.; BEZERRA, D. M.; CAVALHEIRO, L.; PISANO, L. C. Lixo Eletrônico: Agravos a Saúde e ao Meio Ambiente. Ensaios e Ciência: C. Biológicas, Agrárias e da Saúde, v. 19, n. 3, 2015.

Recebido em: 7 de julho de 2018. Aprovado em: 15 de agosto de 2018. 